This item was submitted to Loughborough's Research Repository by the author.

Items in Figshare are protected by copyright, with all rights reserved, unless otherwise indicated.

\title{
A simulation model of Rhizome networks for Fallopia japonica (Japanese Knotweed) in the United Kingdom
}

PLEASE CITE THE PUBLISHED VERSION

PUBLISHER

(C) Elsevier

VERSION

AM (Accepted Manuscript)

LICENCE

CC BY-NC-ND 4.0

\section{REPOSITORY RECORD}

Smith, J.M.D., John P. Ward, Lois E. Child, and M.R. Owen. 2019. "A Simulation Model of Rhizome Networks for Fallopia Japonica (japanese Knotweed) in the United Kingdom”. figshare. https://hdl.handle.net/2134/2366. 
This item was submitted to Loughborough's Institutional Repository by the author and is made available under the following Creative Commons Licence conditions.

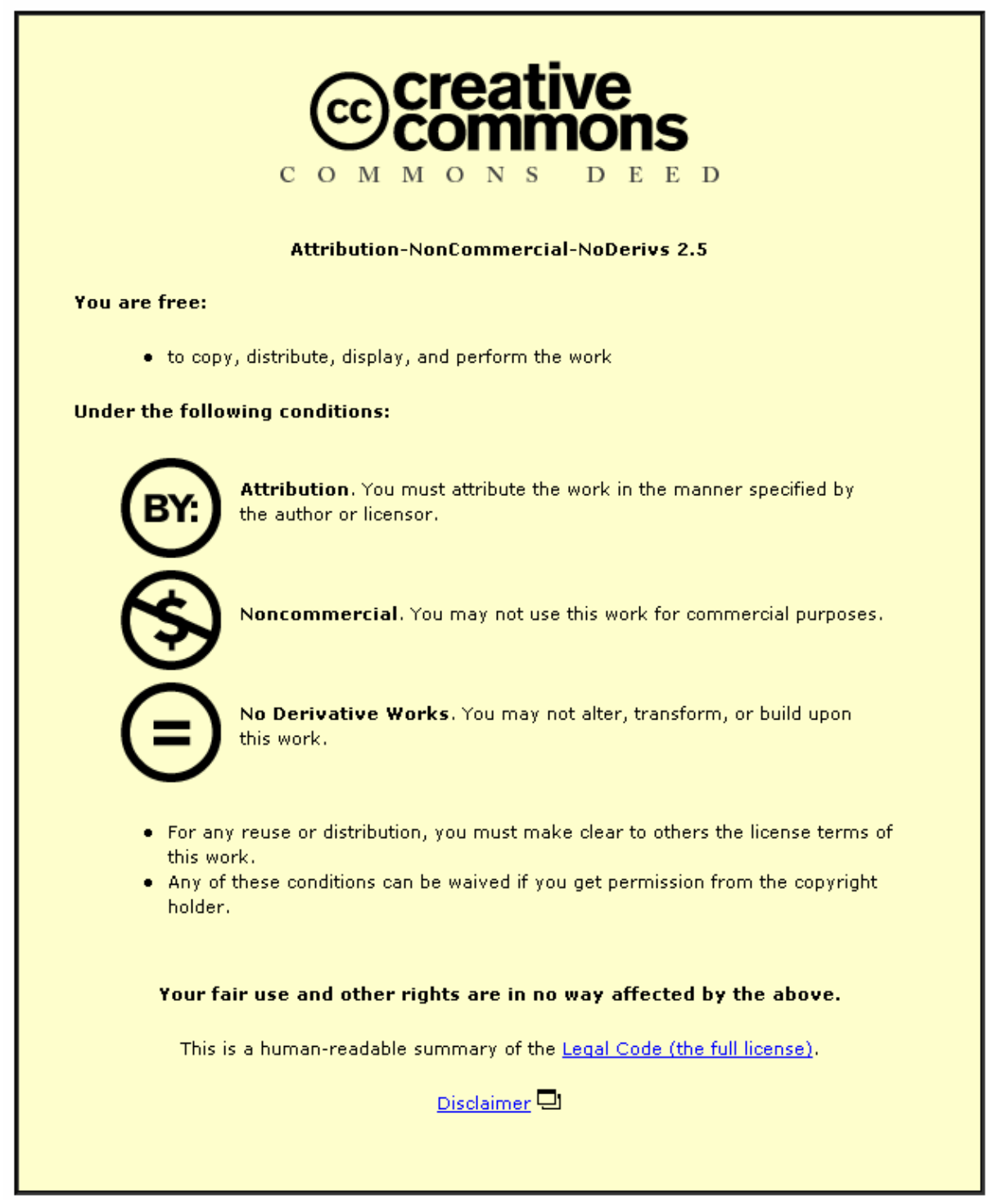

For the full text of this licence, please go to: http://creativecommons.org/licenses/by-nc-nd/2.5/ 


\title{
A Simulation Model of Rhizome Networks for Fallopia japonica (Japanese Knotweed) in the United Kingdom
}

\author{
J. M. D. Smith ${ }^{\text {a }}$, J. P. Ward ${ }^{\text {a }}$, L. E. Child ${ }^{\mathrm{b}}$ and M. R. Owen ${ }^{\mathrm{c}}$ \\ ${ }^{a}$ Mathematical Sciences Department, Loughborough University, \\ Ashby Road, Loughborough, Leicestershire, LE11 3TU, UK \\ ${ }^{\mathrm{b}}$ Centre for Environmental Studies, Loughborough University, \\ Ashby Road, Loughborough, Leicestershire, LE11 3TU, UK \\ ${ }^{\mathrm{c}}$ School of Mathematical Sciences, University of Nottingham, \\ University Park, Nottingham, NG7 2RD, UK
}

\begin{abstract}
Fallopia japonica (Japanese knotweed) is an aggressively invasive herbaceous perennial that causes substantial economic and environmental damage in the United Kingdom (UK). As such, it is of considerable concern to councils, environmental groups, private landowners and property developers. We construct a 3D correlated random walk model of the development of the subterranean rhizome network for a single stand of F. japonica. The formulation of this model uses detailed knowledge of the morphology and physiology of the plant, both of which differ in the UK to that of its native habitat due to factors including a lack of predation and competition, longer growth seasons and favourable environmental conditions in the UK. Field data obtained as a part of this study are discussed and used in the model for parameterisation and validation. The simulation captures the field data well and
\end{abstract}


predicts, for example, quadratic growth in time for the stand area. Furthermore, the role of a selection of parameters on long-term stand development are discussed, highlighting some key factors affecting vegetative spread rates.

Key words: Japanese knotweed, Fallopia japonica (Houtt.) Ronse Decraene, correlated random walk, rhizome morphology, clonal plant, simulation, invasive alien weed

\section{Introduction}

Fallopia japonica (Houtt.) Ronse Decraene (Japanese knotweed) is an aggressively invasive alien weed in the United Kingdom (UK) (Child and Wade, 2000; de Waal, 2001). Native to Japan, the plant was introduced to the UK in 1825 (Beerling et al., 1994; Child and Wade, 2000), becoming naturalised in 1886 (Conolly, 1977). The plant has since become a major problem, both ecologically and economically, throughout the UK and the rest of its introduced range. The problems caused by F. japonica are many and varied. It has been described in the past as the most invasive plant in Britain (Crawley, 1987; Child and Wade, 1999) and impacts on native flora and habitats, increases flood risk, causes physical damage to buildings and property, obstructs public access and even affects sites of archaeological interest (Child and Wade, 2000). The damage that F. japonica can cause in the UK has led to considerable interest from a wide variety of parties including councils, private landowners, property developers and environmental groups, particularly in methods of managing the plant. On a broader horizon, its invasive nature throughout its introduced range has led to the plant becoming a problem throughout Europe, Australia, New Zealand and North America. This has resulted in a wealth of 
legislation being passed to regulate the handling and disposal of the plant. For example, in the UK it is an offence under the 1981 Wildlife and Countryside Act to plant or otherwise cause to grow the plant in the wild (Child and Wade, 2000). However, despite the serious and costly problems it creates, funding for the treatment of sites infested with F. japonica remains difficult to obtain. There is also a need to promote the consequences of procrastination to owners and developers of land when it comes to the timely removal of an infestation from their property. Thus, a tool that could demonstrate the future costs of not treating these sites immediately by illustrating the plant's rapid and problematic spread or that could assess the effects of herbicide treatment would be widely welcomed in the promotion of the problem and the prioritisation of sites for treatment. In the UK, the primary mode of spread of $F$. japonica is vegetative growth which it achieves via the development of extensive subterranean rhizome networks. In this paper we present a 3D correlated random walk model for the development of a rhizome network in the UK.

F. japonica is a rhizomatous perennial giant herb (Child and Wade, 1999) which spreads primarily, in the UK, via vegetative growth of the subterranean rhizome system, but also from stem fragments (Brock and Wade, 1992; de Waal, 2001). These rhizomes (strictly underground stems) send out roots and shoots from their nodes and can extend up to $7 \mathrm{~m}$ away from a main stand (group of individual plants growing in close proximity) and up to $2 \mathrm{~m}$ deep (Child and Wade, 2000). F. japonica has the ability to reproduce both sexually (requiring a male and female plant) and vegetatively in its native range. However, genetic analysis of all British F. japonica plants observed to date has confirmed that, within the British Isles, the population is clonal (Hollingsworth and Bailey, 2000). Pysek (1997) suggested that clonal plants 
often make poor invaders since specialised seed dispersal structures represent an advantage for seeds over vegetative propagules. A seed is more resistant to frost, desiccation and mechanical damage than most vegetative propagules (fragments of stem or rhizome) and for this reason a vegetative propagule may be less effective in dispersal. However, Pysek (1997) also observed that clonal plants made up $60 \%$ of the deliberately introduced alien flora of Auckland, New Zealand compared to $40 \%$ of accidental introductions. It would appear that, in terms of establishment, clonal plants have an advantage over non-clonal plants where deliberate introductions are made. The traits of an invasive plant which provide some prediction of invasion success have been widely discussed (Crawley, 1987, 1989; di Castri et al., 1990; Mack, 1986; Pysek et al., 1995). Child (1999) showed that F. japonica satisfies many of these criteria in that it is perennial, has rapid growth, is a strong competitor and is capable of reproducing vegetatively. As is evident in the field, the dispersal of vegetative propagules due to the action of water and transportation by human activities has resulted in F. japonica becoming a very successful invasive species, despite being clonal in nature.

There is a large amount of additional literature on F. japonica covering areas including the ecology of the plant (Beerling et al., 1994; Child and Wade, 2000), its reproductive strategies and capabilities (Brock and Wade, 1992; Beerling et al., 1994; Brock et al., 1995; Hollingsworth and Bailey, 2000; de Waal, 2001; Price et al., 2002; Forman and Kesseli, 2003), management techniques and their effectiveness (Child and de Waal, 1997; Seiger and Merchant, 1997; Child et al., 1998; Dawson and Holland, 1999; Brabec and Pysek, 2000; Hathaway, 2000; Child et al., 2001; Green, 2003), the importance of scale in the interpretation of distribution maps and model output (Collingham et al., 
2000; Hulme, 2003; Thuiller et al., 2003), its effects on riparian habitats (Pysek and Prach, 1993; Dawson and Holland, 1999; Tickner et al., 2001) and its genetic makeup and hybridisation (Beerling et al., 1994; Hollingsworth et al., 1998; Kim and Park, 2000). There is also a growing amount of data on the distribution of the plant throughout the British Isles collected for or by groups such as the City and Council of Swansea, the Cornwall Knotweed Forum and the Environment Agency. However, despite increasing interest and literature on the plant, there are few papers on the mathematical modelling of the spatial spread of $F$. japonica. Most of these are concerned with its advance on a regional, national or continental scale (see, for example, Beerling (1993); Beerling et al. (1995); Collingham et al. (2000)). There seems to be only one example of modelling the spread on a local scale, namely Adachi et al. (1996b), yet it is at this scale that the modelling would be most useful to many interested parties. In Adachi et al. (1996b), a two-dimensional stochastic model for the development of a rhizome network on Japanese plants in their native range is constructed. Their model is similar in principle to the one presented herein and uses field data gathered from the slopes of Mount Fuji to build a model based on a number of iterated rules. However, there are a number of issues that somewhat limit the applicability of Adachi et al.'s model to $F$. japonica in the UK:

(1) The field data from Mount Fuji that the model of Adachi et al. was based upon is not applicable to the UK problem for two main reasons: firstly, their fieldwork was carried out on Reynoutria japonica (syn. F. japonica) that was actually closer in nature to $F$. japonica var. compacta (N. Adachi, personal communication, 1997), the morphology and physiology of which contrasts markedly to the F. japonica var. japonica considered in 
this UK study; secondly, the environmental conditions are much harsher for the plant in Japan than in the UK. For example, Bailey (2003) has shown that altitude affects the plant's growth significantly (due to a contraction of the growth period). There is also a much greater incidence of predation from invertebrates, such as chrysomelid beetles, sawfly and Japanese swift moth larvae (Bailey, 2003), and fungi such as some Puccinia species and Phyllosticta rayoutina (Child and Wade, 2000). This may be one reason why the size of the plant and its growth habit in the UK differ to those in its native range; in Britain and Northern Europe, $F$. japonica stems may grow up to $3 \mathrm{~m}$ tall and form densely packed crowns at their base, but Japanese stands tend to consist of sparse, single, much shorter stems (Bailey, 2003).

(2) A key feature of Adachi et al.'s model is the formation of central dieback that is primarily driven by the growth pattern of the rhizome system (Adachi et al., 1996a), forming a rough annulus of aerial stems; this feature has not been recorded in UK plants.

(3) Some of the modelling assumptions made in Adachi et al. (1996b) do not hold for the UK problem including: it is well-known that crowns in the UK have a lifespan that far exceeds the 5 years assumed in Adachi et al.'s work (one possible explanation for the lack of central die-back formation); observations from this study show that for the UK strain not every rhizome produces a crown; rhizome segments are not generally straight (see Figure 1); and there is no observed increase in rhizome length with branching order (see later).

(4) Rhizomes can grow up to $2 \mathrm{~m}$ deep (Child and Wade, 2000), circumnavigating obstacles such as walls and building foundations. This means that a two-dimensional model such as that proposed by Adachi et al. is limited 
in its usefulness for such cases and is the main reason why we adopt a three-dimensional approach to modelling the rhizome network.

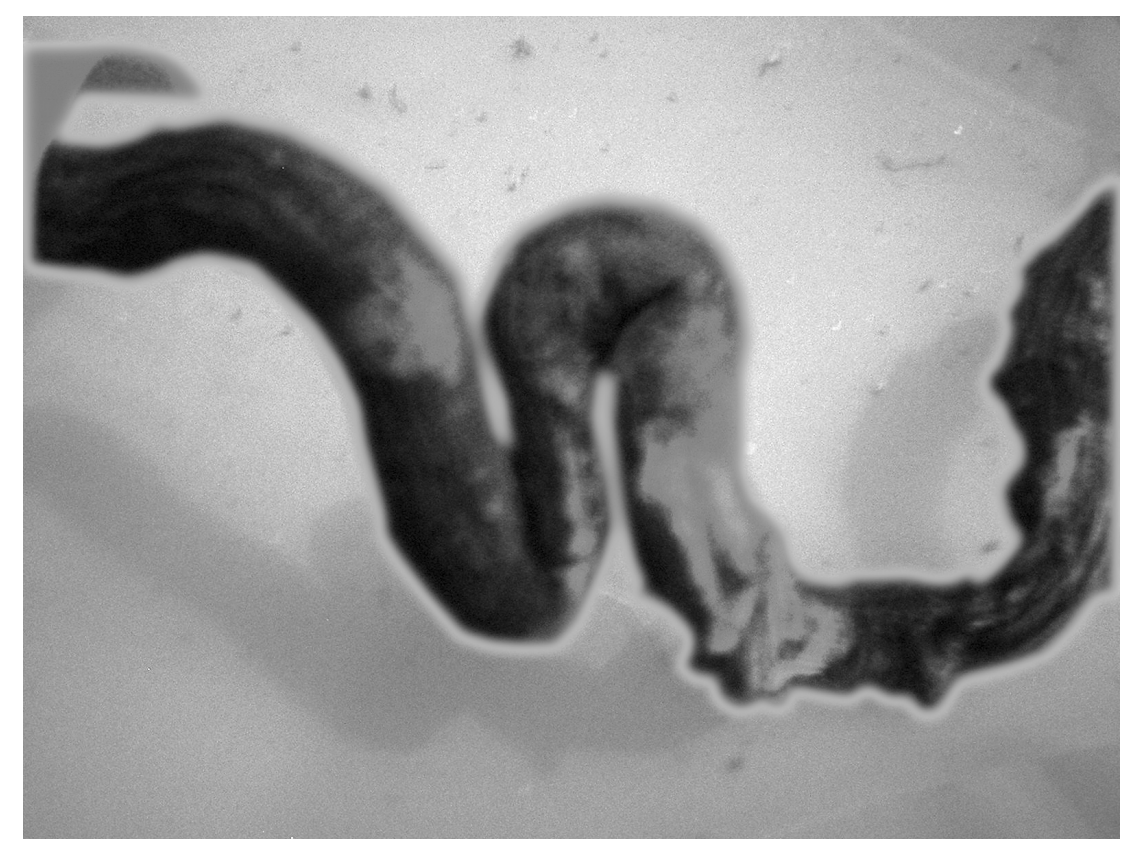

Fig. 1. An example of the extreme changes possible in the direction of growth of a rhizome segment in the UK. Image width approximately $15 \mathrm{~cm}$.

Given the differences in the plant's behaviour between its native and introduced range, it is necessary to construct a model that is more relevant to the conditions and plant physiology found in the UK. Like Adachi et al., we focus on the growth of the subterranean rhizome network since the location and spread of the stems is a direct consequence of the development of this network. However, in order to do so it is necessary to have a thorough understanding of the network's morphology and physiology. At present there exists very little data on the behaviour of the rhizomes beneath the soil, besides work on genetics and chemical content, yet the 'clonal growth parameters' (rhizome segment lengths, branching angles and number of daughters) have a critical impact on the way in which rhizomatous plant species grow in terms of size and shape (Cain, 1990). To address this issue, field data were obtained for use 
in the parameterisation of the model: this will be discussed in Section 2. In Section 3 we present a 3D correlated random walk model for the development of a rhizome network in the UK strain. The results are analysed in Section 4 and conclusions drawn in Section 5.

\section{Field Data}

The use of field data for both validation and parameterisation is very important for the modelling in later sections. As criteria for suitable sites, stands were sought that were i) located in a representative environment and ii) free of the influence of management (some techniques of which can actually assist the development of the plant if not applied correctly or if application is terminated prematurely). Two suitable sites were studied.

\subsection{Survey 1}

The first site was selected primarily for rhizome network extraction and consisted of a large stand of F. japonica (approximately $200 \mathrm{~m}^{2}$ in area) in a woodland/road verge habitat near Penhallick in Cornwall (Tab. 1). It contained a dense thicket of old, dead canes from previous years and abundant evidence of new stem growth from the present year's growth season. The characteristic bright-red/pink buds and stems, ranging from ground level to over $30 \mathrm{~cm}$ in height, could be seen throughout the stand. A number of associated plant species were present within the stand including Hemlock Water Dropwort (Oenanthe crocata), Hart's Tongue Fern (Phyllitis scolopendrium), Ivy (Hedera helix) and Hard Fern (Blechnum spicant). 
General Site Information

Date of Survey $\quad 23^{\text {rd }}$ Feb 2004

O.S. National Grid Reference 204/774180

Location $\quad$ Penhallick, Cornwall, UK

Longitude 50:01:15N (50.0207)

Latitude 5:06:29W $(-5.1081)$

Altitude Approx. $70 \mathrm{~m}$ above sea-level

Average Temp. (Feb)* $\quad 3.5-8.5^{\circ} \mathrm{C}$

Average Temp. (Annual)* $\quad 7.9-13.3^{\circ} \mathrm{C}$

Habitat Type Woodland/Road verge

Soil Type $\quad$ Loam plus dumped items including

slate, bottles, domestic china and a

variety of metal objects

Approximate Stand Area $\quad 200 \mathrm{~m}^{2}$

Table 1

General information about the chosen study site. ${ }^{*}$ Data taken from nearest weather station (St. Mawgan) on the Meteorological Office website (http://www.metoffice.gov.uk).

The specific area designated for rhizome extraction was a smaller zone on the periphery of the main stand, consisting of several smaller crowns that were thought likely to be interlinked by a continuous and traceable rhizome 
network (Fig. 2). The topsoil was a loam but buried within it was a large quantity of slate, rubble, bottles, domestic china and a variety of metallic objects, suggesting that the stand may well have originated from dumped household material. This is a common occurrence in infested areas.

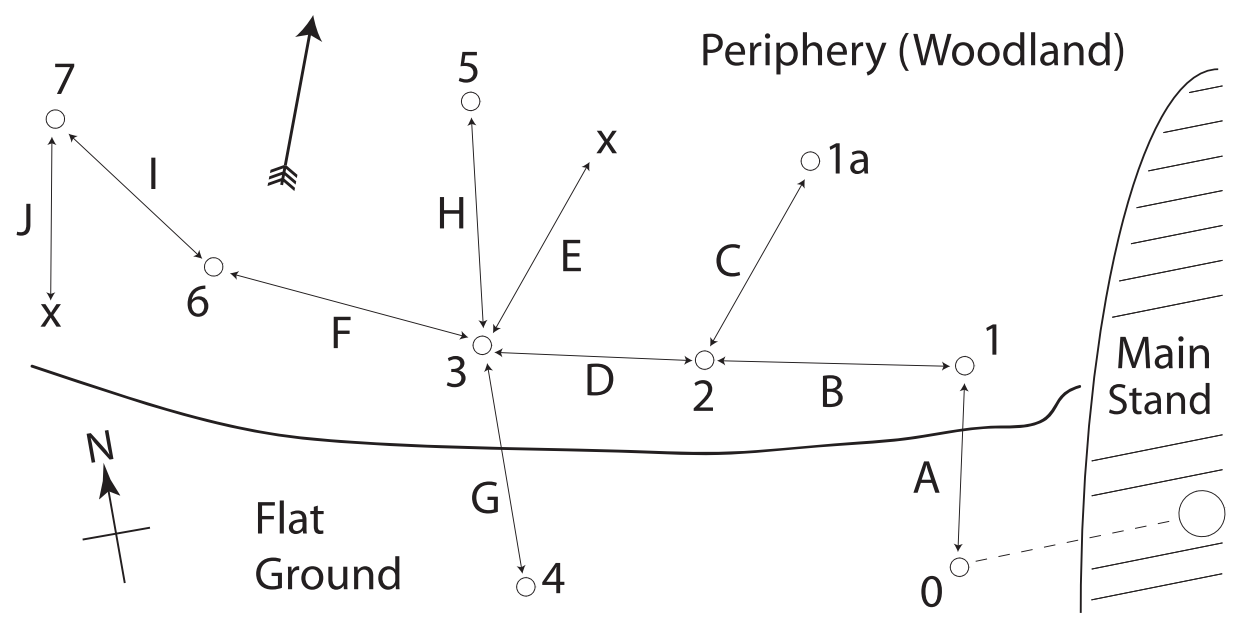

Fig. 2. A sketch map of the site. Crown 0 is the oldest crown in the chain and connects to the main stand as shown by the dotted line. Single stems are marked with an ' $\mathrm{X}$ ' and the feathered arrow marks the downhill direction. Distances of nearby crowns (A-J) were $0.45 \mathrm{~m}, 0.40 \mathrm{~m}, 0.27 \mathrm{~m}, 0.80 \mathrm{~m}, 0.40 \mathrm{~m}, 1.60 \mathrm{~m}, 1.60 \mathrm{~m}, 0.60 \mathrm{~m}$, $1.00 \mathrm{~m}$ and $0.90 \mathrm{~m}$, respectively. A-J also represent the network's connectivity. Heights of the previous year's stems ranged from 1.3-2 m.

Prior to unearthing the rhizome network, some surface measurements were taken: the density of new stem growth in the main stand was determined using quadrat surveys, a transect of the stand was taken counting the incidence of crowns and some nearest-neighbour crown separations were obtained along with stem dimensions.

Following these surface observations the rhizome network itself was unearthed layer by layer by carefully 'cutting' the system out of the soil with a pressurewasher. This method had the advantage of enabling the extraction of entire 
sections of the network intact whilst minimising the damage to them. Figure 3 shows an example of a small part of such a network section.

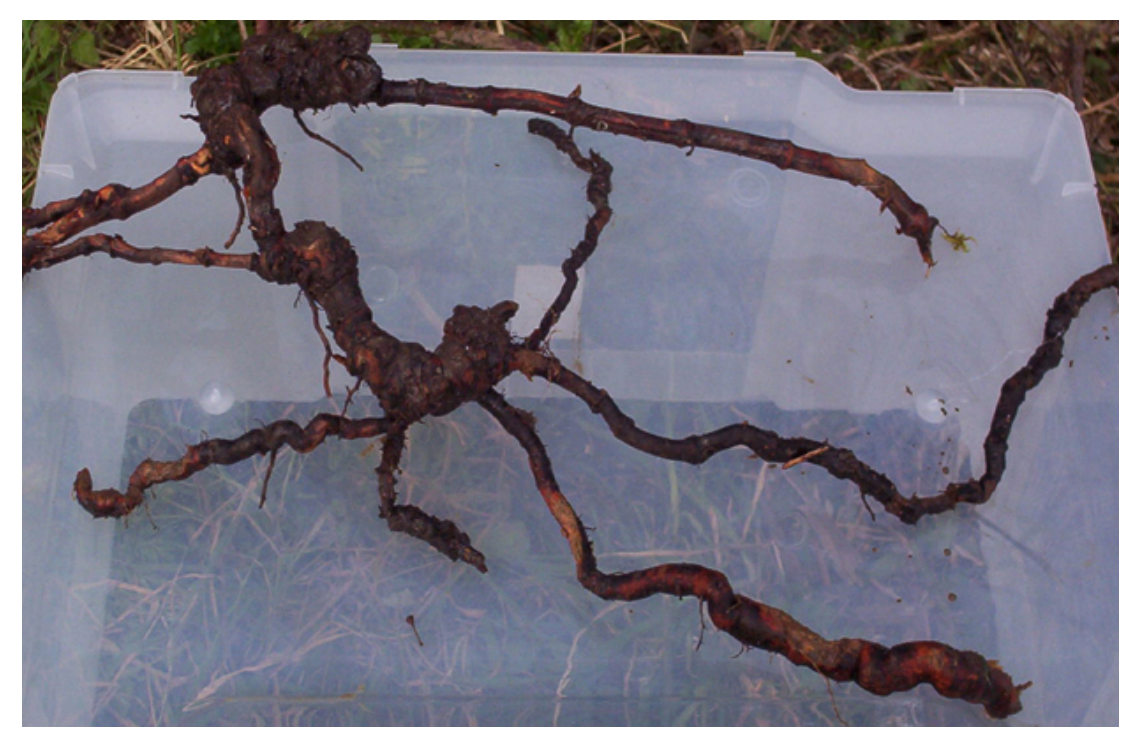

Fig. 3. An example of part of a network sample. Image width approx. $90 \mathrm{~cm}$.

Samples were taken away, cleaned and the network reconstructed as far as possible. Various morphological properties of the network were then measured including:

- If the rhizome morphology was sufficiently clear, the relationship between two connected segments was recorded (see Fig. 4). A 'daughter' segment stems from one of the lateral buds of its 'parent', whereas a 'continuation' segment is the post-branching point continuation of the parent segment.

- Segment Length. Here, a segment is the part of the rhizome between two branching points or between a terminus and a branching point. Only those with unbroken tips and bases were included in the statistical analyses.

- Branching Angle. The angle at which a daughter segment branched from its parent.

Also recorded, where possible, were the internode length, segment diameter, 


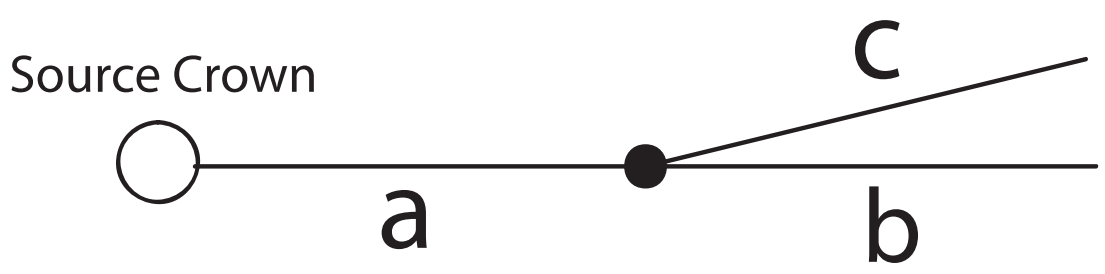

Fig. 4. Segment 'a' is a primary rhizome segment coming from a source crown. It is also the parent of the continuation and daughter segments, ' $b$ ' and 'c' respectively. branching direction, segment depth, the number of buds along a segment and the distance between them, crown diameter, the height of old stems, the number of previous stems from each crown and the distance between them, and the number of existing buds on each crown (both dormant and active).

Figure 5 shows the distribution of segment lengths found in our data. We note that direct comparison with the equivalent data from Adachi et al. (1996b) is not possible here due to contrasting definitions. Whilst the maximum segment length observed was $81.1 \mathrm{~cm}$, about $95 \%$ of the data is actually within the 0.6-41 cm range. The longer outliers of $72.8,75.3$ and $81.1 \mathrm{~cm}$ were those connected directly to a crown and whose path led to other crowns eventually. It is clear from the distribution that segment lengths tended to be much shorter than this in general with the modal group being the $0-5 \mathrm{~cm}$ group. No clear relationship between the length of a parent rhizome and either its continuation or a daughter rhizome was found, constituting direct evidence that increasing length with branching order is not a valid assumption for F. japonica in the UK.

Figure 6 shows the branching angles from our data (black) and compares them with the corresponding distributions obtained by Adachi et al. (1996b) (grey) for $R$. japonica. Clearly these contrast greatly, highlighting one of the 


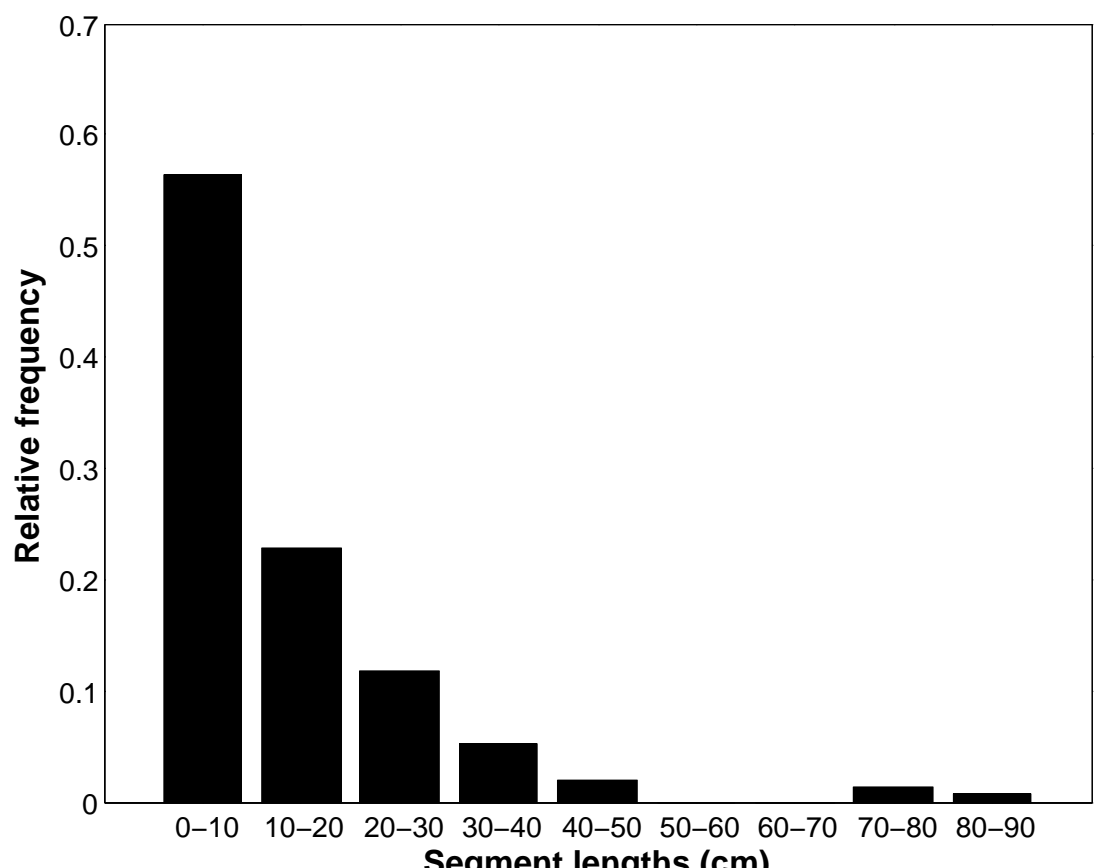

Fig. 5. The relative frequency distribution of segment lengths from the field data. For $n=154$ samples, a mean length of $12.94 \mathrm{~cm}$ with a standard deviation $\sigma=13.90$ and a range of $0.6-81.1 \mathrm{~cm}$ was found.

morphological differences between the two varieties. Most of the angles in their work were between $30-50^{\circ}$. However, the modal group for the branching angles for $F$. japonica on this site was $5-15^{\circ}$. There were also many smaller and $90^{\circ}$ angles recorded, whereas Adachi et al. found few of either. A $\chi^{2}$ test yields $\chi^{2}=26.3463$ (9 degrees of freedom) so that with $p \leq 0.01$, we can state with 99\% confidence that the difference in the distributions between the data in this study and that of Adachi et al. is statistically significant.

In addition, our data show that rhizome branching angles and segment lengths were not correlated over time, either with themselves or each other. These are key assumptions of a random walk model and therefore it is reasonable to consider their selection in the model as a series of random draws from the frequency distributions shown. We note that modifying the code to incorporate 


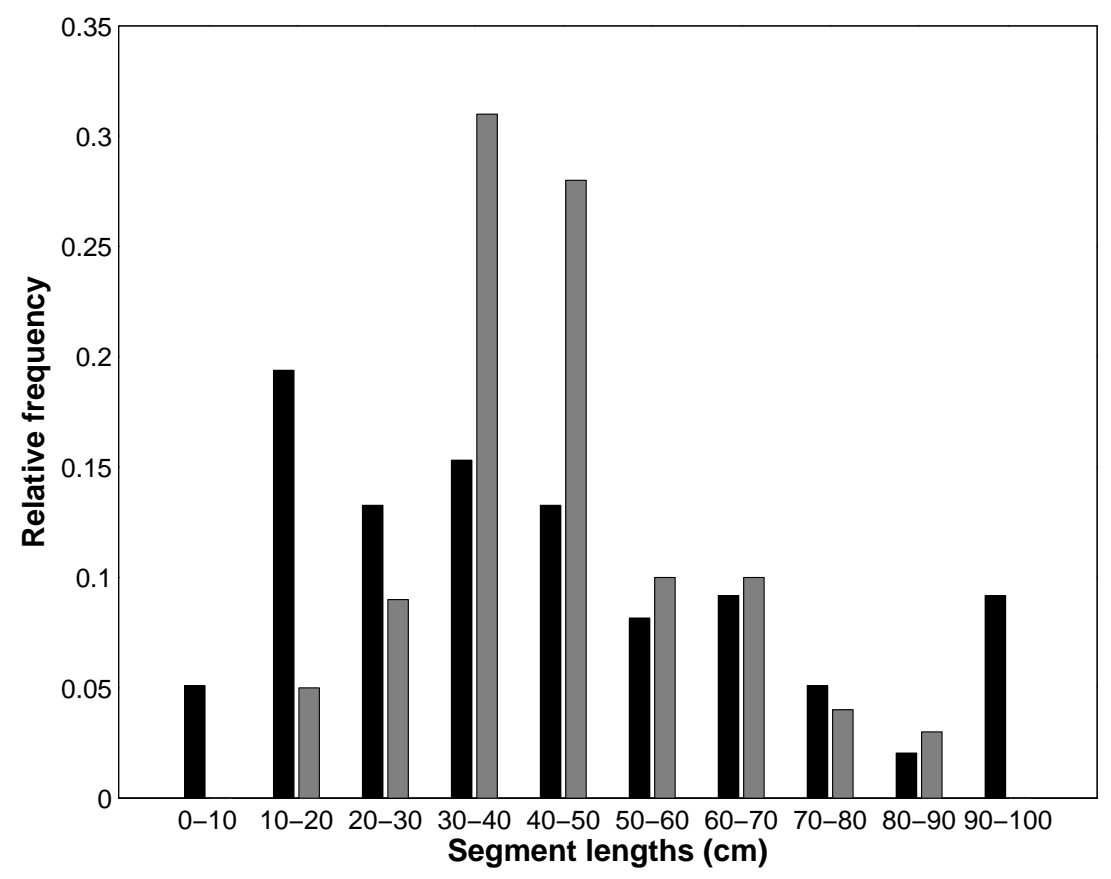

Fig. 6. The distribution for branching angles obtained from our field data is shown here in black. Here, $n=98$ samples had a mean of $40.87^{\circ}$ with $\sigma=25.20$ and a range of $6-90^{\circ}$. The corresponding data from Adachi et al. is shown in grey for comparison. In general, segment lengths were found to be much shorter in this survey than that of Adachi et al.

more data is a straightforward process.

Some other results which may be of more general interest include 1437 samples of internode lengths yielding a mean of $2.04 \mathrm{~cm}$ with standard deviation $1.17 \mathrm{~cm}$ and a range of $0.3-8.7 \mathrm{~cm}$, and 229 segment diameter samples yielding a mean of $0.62 \mathrm{~cm}$ with standard deviation $0.40 \mathrm{~cm}$ and a range of $0.2-2.2 \mathrm{~cm}$.

\subsection{Survey 2}

An investigation of crown densities and rhizome extension rates was carried out at a second stand in Shepshed (Leicestershire). Given that crowns may 
grow to become very large in size, crowding can become an important factor in the plant's crown formation strategy and is therefore an essential component to include in any modelling. The crown density is thus an indicator of how important this crowding is. The area of the convex hull (which can be viewed as the shape made by an 'elastic band' stretched around the stand) defined by the stand's constituent crowns and the number of crowns this encapsulated were recorded. A stand area of $55.74 \mathrm{~m}^{2}$ contained 79 crowns, 19 of which made up the convex hull. This gives a crown density of 1.417 crowns per square metre including perimeter crowns, or 1.076 crowns per square metre using the internal crowns only. We therefore choose an internal crown density of 1.08 crowns per square metre to act as a benchmark for model validation.

This survey was carried out during November, at the end of the plant's growth season. This meant that the current year's rhizome growth was still identifiable by its white, fleshy appearance and soft texture (see Child and Wade (2000)). A section of the stand was unearthed and samples of this new growth were collected, cleaned and measured. Their lengths give an idea of typical growth lengths for a single growth season, a crucial parameter for the models. A sample size of 17 yielded a mean segment length of $17.37 \mathrm{~cm}$ with a standard deviation of $9.22 \mathrm{~cm}$ and a mean segment diameter of $0.34 \mathrm{~cm}$ with a standard deviation of $0.1 \mathrm{~cm}$. The new growth was found to have 131 clearly defined internode samples, yielding a mean internode length of $1.74 \mathrm{~cm}$ with a standard deviation of $0.95 \mathrm{~cm}$. 


\section{A Correlated Random Walk Model}

In this section we develop a 3D correlated random walk (CRW) model to describe the subterranean rhizome network development. Random walks are discrete-time stochastic processes consisting of a sequence of discrete steps in random directions at each time-step. For simple random walks, the selected direction at any given time-step is independent of any previous choices of direction. In contrast, a correlated random walk changes direction in subsequent time-steps randomly, but with bounded range dependent on the previous direction of travel. Such an approach has been used to model butterfly (Kareiva and Shigesada, 1983) and amoeboid movement (Hall, 1977) as well as a number of other species of animal. Cain (1990) was the first to apply this type of model to the vegetative spread of clonal plants. He constructed a CRW model in $2 \mathrm{D}$ for the development of a rhizome network in the old-field perennial Solidago altissima (goldenrod), the parameter values of which were obtained directly from field studies. Here we take a similar approach but construct a three-dimensional CRW model with a number of additional features for the development of $F$. japonica rhizome networks.

Rhizomes can grow up to $2 \mathrm{~m}$ deep (Child and Wade, 2000), meaning that their vertical growth can play as important a part in the development of the network as the horizontal growth; for example, in overcoming obstacles in the plant's path such as walls or roads that might typically affect growth patterns at this scale. Additionally, in agreement with the observations of Adachi et al. (1996a) our data show no crowns developing below $30 \mathrm{~cm}$ from the surface. It is thus necessary that the model can accommodate this key feature of the rhizome's development and we use this assumption to impose a limit on the depth 
at which crowns may form. Furthermore, the field data feature significantly in the model and in many cases these data by their very nature implicate the use of a three dimensional model. For example, the segment lengths are purely the length of a segment, not the distance in the $x-y$ plane that the segment tip was separated from its base. This is also true of the branching angles which were measured relative to their parent segment, not a fixed 2D axis. The use of three dimensions allows us to use these data, thereby making the model closer to the biology. Other important properties of the plant that should also be included in the model are the erratic changes in direction that rhizomes make, the formation of crowns to facilitate the extension of the network, typical branching angles and segment lengths, and a range of other empirically determined physiological parameters.

In the application of the CRW model, a series of rules and events are carried out at each step of a discrete-time simulation. Table 2 details the standard parameter values, some of which were extracted from the field data. The simulations focus on the development of a stand of $F$. japonica from a single pioneering rhizome fragment to a full system of mature crowns interconnected by a growing and branching rhizome network. The main rules of the model are:

(1) For the initial condition, we have a crown formed at the origin which produces a fixed number of primary rhizomes. A radius is randomly chosen for a circular region surrounding it from a look-up table generated from the field data on nearest neighbouring crown separations. This forms an area surrounding the crown which represents a region subject to intraspecific competition, denied light by leaf cover and suffering impaired generation of new stems due to ground litter, thereby recreating a simple 


\begin{tabular}{|c|c|c|}
\hline Parameter & Std. Value & Comments \\
\hline Rhizome extension per year, $l$ & $0.174 \mathrm{~m}$ & From fieldwork \\
\hline Nearest-neighbour crown separations & $0.17-1.44 \mathrm{~cm}$ & From fieldwork \\
\hline Trans-network crown trigger length, $d$ & $0.8611 \mathrm{~cm}$ & From fieldwork \\
\hline Primary segments from new crowns, $r$ & 2 & From fieldwork \\
\hline Probability of forming a crown, $c$ & 0.0145 & Estimate \\
\hline Maximum Gravelius branching order, $\gamma$ & 3 & From fieldwork \\
\hline Maximum crown formation depth, $h_{c}$ & $30 \mathrm{~cm}$ & From fieldwork \\
\hline Maximum deviation of growing tips, $\delta$ & $20^{\circ}$ & Estimate \\
\hline Min. depth limit of rhizome growth, $h_{\min }$ & $0 \mathrm{~m}$ & $\dagger$ \\
\hline Max. depth limit of rhizome growth, $h_{\max }$ & $-2 \mathrm{~m}$ & $\dagger$ \\
\hline Prob. of no growth this time-step, $p_{p}$ & 0.01 & Estimate \\
\hline Branching trigger lengths & $0.6-81.1 \mathrm{~cm}$ & From fieldwork \\
\hline Prob. of segment dying, $p_{d}$ & 0.0083 & $\ddagger$ \\
\hline
\end{tabular}

Table 2

Standard simulation parameters. Standard simulations were run for 200 time-steps (1 time-step $=4$ months). Estimated parameters were chosen such that, on average, a crown density comparable to that observed in the field was obtained. ${ }^{\dagger}$ See Child and Wade (2000). ${ }^{\ddagger}$ Taken to be $l / 7$ for expected length of $7 \mathrm{~m}$. 
crowding response.

(2) Primary rhizomes are randomly assigned a direction of growth and a branching trigger length is randomly drawn from a look-up table of segment lengths derived from our field data. These then extend by the growth increment $l / 3$ from the crown.

(3) Each segment is checked to see if its branching trigger length has been exceeded. If so, the segment permanently ceases any further extension, produces a 'bud' at this point and forms a 'continuation' segment which continues growing in approximately the same direction as the parent segment. In the field, buds are formed in the autumn. The plant then over-winters and the buds may be activated in the following growth season (Child and Wade, 2000). The simulated buds are therefore activated once they are a full year old (3 time-steps later). When this occurs a new daughter rhizome begins to grow out from this point, the branching angle of which is randomly chosen from a look-up table derived from the field data distribution.

(4) Each segment tip is tested for crown viability to see if it should form a crown at its tip. In the plant, stem formation is primarily regulated by the levels of growth hormones present near buds (apical dominance). In the simulation there are three criteria:

(a) The segment's tip must not lie within one of the areas subject to intraspecific competition (see step 1).

(b) The length from the tip to its parent crown traced back along the rhizome network must be greater than a minimum distance based on field data. This represents, very simply, apical dominance.

(c) The tip must lie within certain empirically-obtained depth limits.

If these criteria are met then there is a chance that a crown will form. 
This new crown would then begin sending out its own primary rhizomes in the same way as the initial crown (step 2).

(5) Segments 'die' (become permanently inactive) via two mechanisms: i) when they have reached their branching trigger length at the maximum prescribed branching order from their parent crown (in our fieldwork this was not seen to exceed 3 orders); ii) there is a small chance of each rhizome segment expiring irrespective of its branching order at each time-step.

(6) The order in which branching and crown generation are carried out is randomized so as to eliminate any bias that might occur as a result of a fixed order. The sequence of rhizome segments to which these events are applied is also randomised at each time-step.

(7) All active segments then undertake one step of a 3D correlated random walk. The deviation of direction is weighted to lie within a fixed range of the previous direction of growth (see Figure 7) and is selected randomly from a uniform distribution between those limits. For every growth direction decided upon, a check is subsequently made to make sure that it falls within the required depth limit of $2 \mathrm{~m}$ (the typical limit of live specimens). If it does not, the depth coordinate is changed to lie on the boundary. This has the effect of shortening that particular step's growth length.

(8) Steps 3-7 are then iterated for the required number of time-steps and a network of interconnected crowns and rhizome networks is developed.

We take one time step to represent 4 months such that 3 time-steps encompasses a full growth cycle of one year. We then set the extension per unit time of rhizomes to be the mean of our new growth data divided by 3 . This meant that extension per unit time was short enough to provide a reasonable scope 


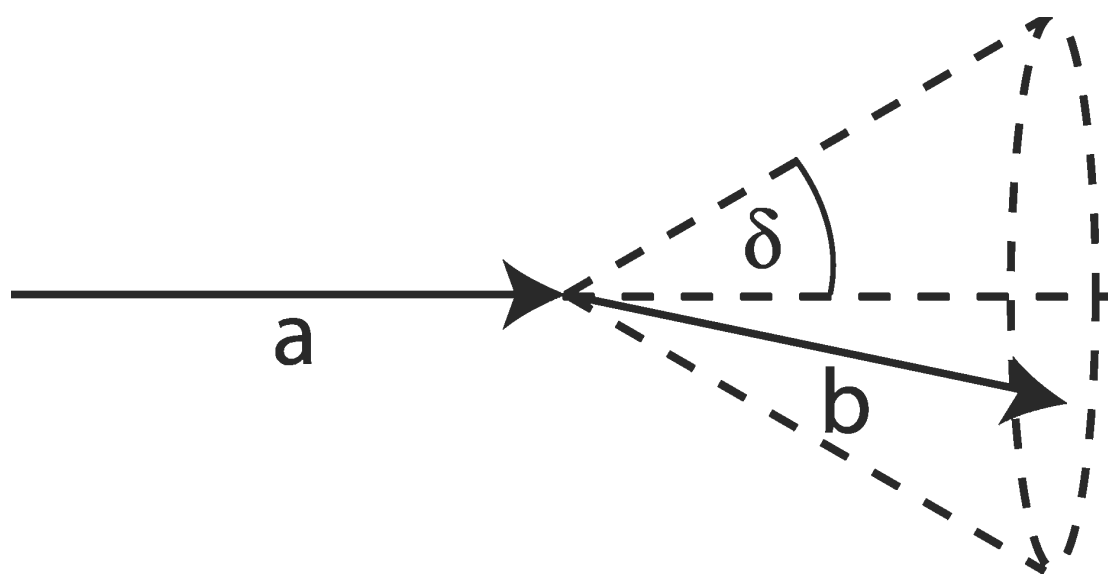

Fig. 7. An example of the growth in one time-step. Here $\mathbf{a}$ is the previous growth vector and $\mathbf{b}$ is a potential choice of direction for this time-step. The dashed lines represent the maximum possible change of direction in this plane for this step and the continuation of the previous growth vector.

for rapid change of direction whilst retaining a convenient unit of time. Figure 8 shows a typical output of the simulation after 70 time-steps (about 23 years) for clarity.
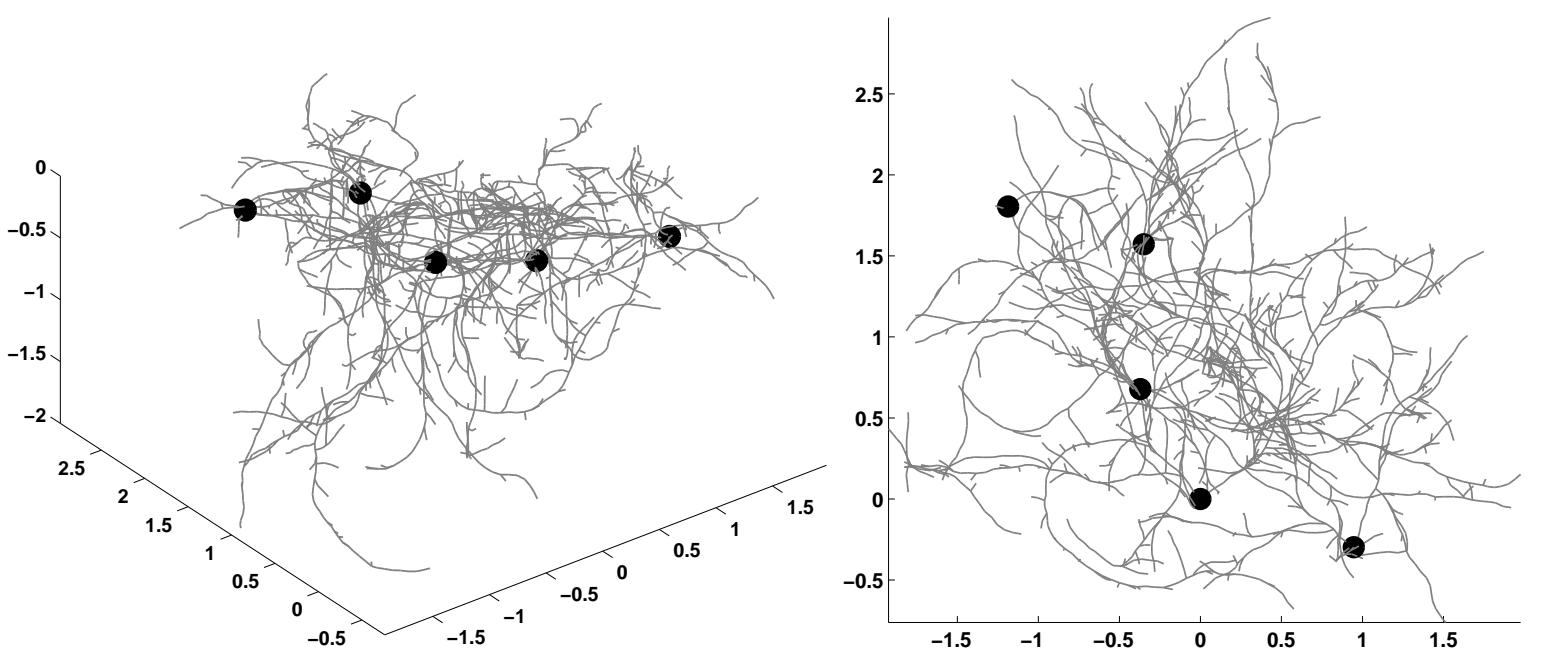

Fig. 8. A typical output of the simulation at 70 time-steps ( $\approx 23$ years $)$. A top-down view is shown on the right. Crown locations are marked with a large black circles and rhizomes are represented by the thin, grey lines. 


\section{Results}

In this section we look first at the results obtained from simulations of the model run under the standard parameter values and go on to discuss the effects of varying some of the unknown parameters on the model output.

\subsection{Standard Simulations}

Figure 9 shows the mean crown density (left) and mean area evolution (right) with time for a typical simulation of the model run under the standard parameter values (see Table 2). It can be seen that the crown density tends to settle at around 1 crown per square metre from around $t=120$ onwards. This conforms with the density observed in the field of 1.08 crowns per square metre. Fitting a least-squares polynomial to the mean area with time yields a strong correlation to a quadratic expansion of area in time $\left(R^{2}=0.999\right)$. Here, the area of the stand is taken to be the area of the convex hull formed around the simulated stand's constituent crowns. This quadratic expansion in area, $A$, occurs in all simulations, the important consequence being that in large time

$$
A \approx \alpha t^{2}
$$

for some constant $\alpha$. This constant indicates how fast a stand will grow and, consequently, it is a useful parameter for characterising the effects of the unknown parameters in the parameter surveys below. We note that for the statistical analysis, only those trials of the simulation that did not fail (whole stand dies) are included so as not to skew the statistics. Indeed, the field- 
work focussed only on thriving stands. For 19 trials run under the standard parameter values, no incidences of the entire stand dying were observed.
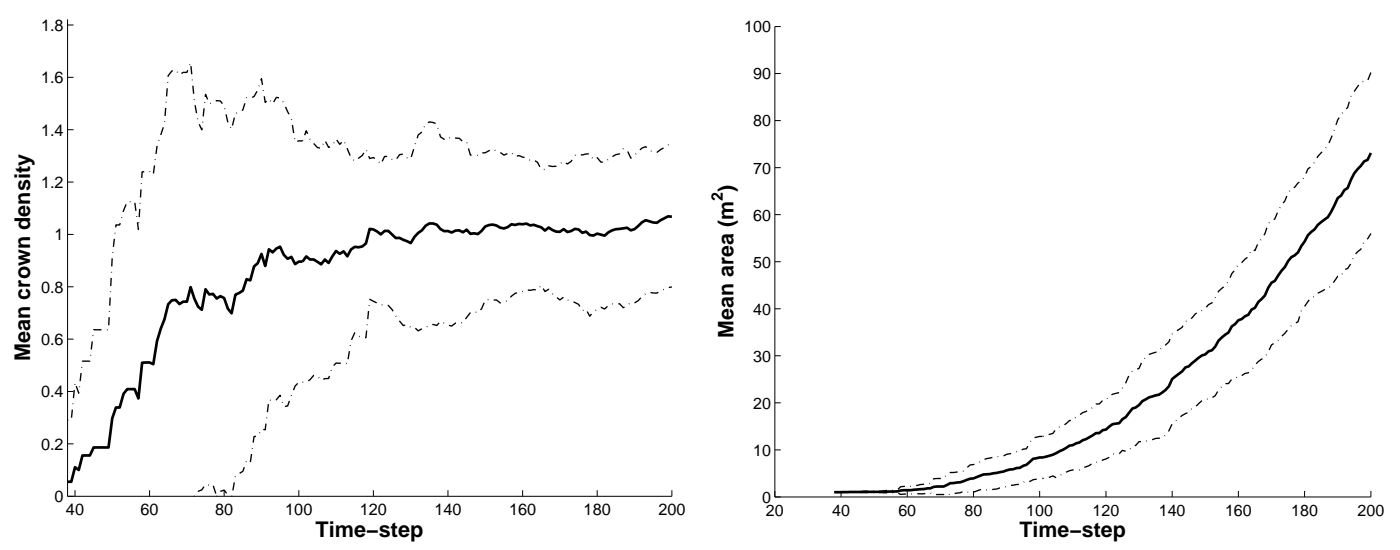

Fig. 9. Mean crown density (left, 18 trials per data point) and mean area evolution (right, 14 trials per data point) (solid lines) and \pm 1 standard deviation (dashed lines) against time for simulations of the model run under the standard parameter values (Tab. 2). The quadratic function yielding the best least-squares fit $\left(R^{2}=0.999\right)$ to the mean area evolution results is $A(t)=0.0035 t^{2}-0.4032 t+12.8568$ for $t \in[38,200]$.

\subsection{Parameter Surveys}

The use of our field-data in the model meant that we were able to obtain appropriate values for the majority of the parameters in the model. There are only three unknown parameter values: $c, \delta$ and $p_{p}$ (see Tab. 2). With so few unknowns it is therefore possible to carry out an extensive study on the effect of these parameters. The stand characteristics studied in the parameter surveys below are crown density and stand growth parameter $\alpha$ (equation 1). Statistics were taken from those simulations that produced fully established stands. This was defined to be stands that had exhibited area expansion for at least 50 time-steps. Stands that had not exhibited area expansion for at least 
50 time-steps were omitted from the statistics. For stands that completely died out we note the number of trials included in the statistics in the text below.

\subsubsection{Maximum Deviation, $\delta$}

Figure 10 shows the relationship between the maximum deviation (angle of maximum turn) allowed in the correlated random walk, $\delta$, and the mean crown density (left) and $\alpha$ (right).
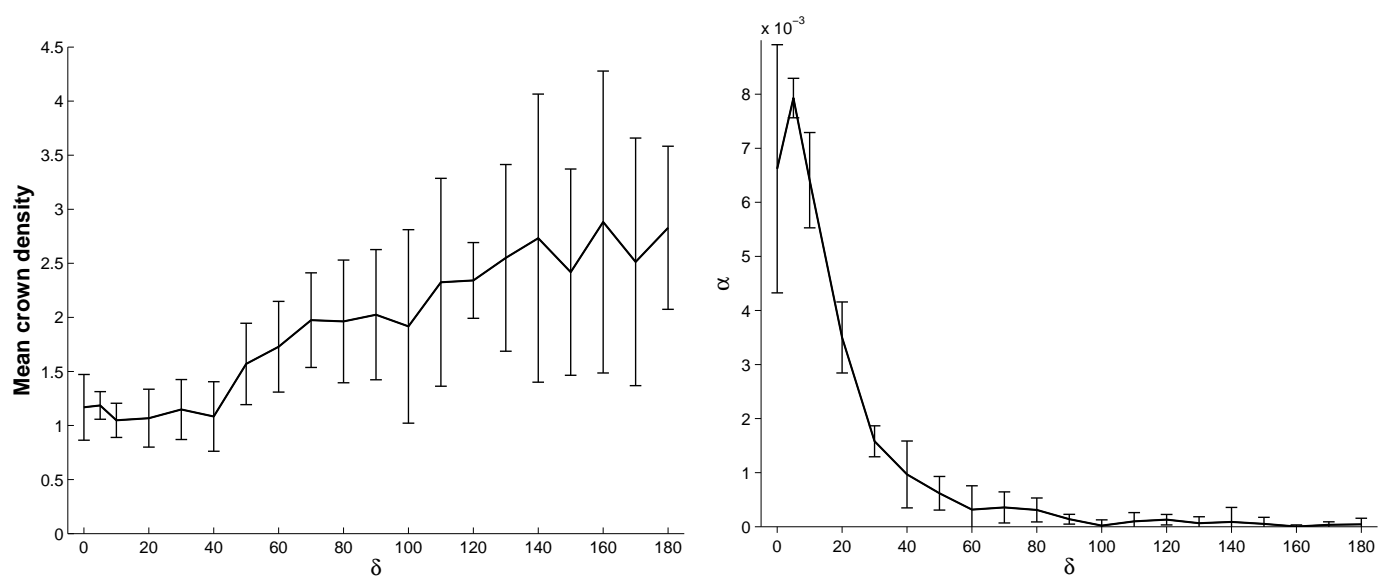

Fig. 10. The effects of $\delta$ (in degrees) on mean crown density (left, 5-18 trials per data point) and growth parameter $\alpha$ (right, $3-14$ trials per data point). Bars indicate \pm 1 standard deviation. Other parameters in the trials are as given in Tab. 2.

For $0 \leq \delta \leq 40$ the predicted crown density remains almost constant at just over 1 crown per square metre. For $\delta>40$ the general trend is monotonically increasing with greater variability exhibited for larger $\delta$. This is due to large $\delta$ resulting in a slower rate of area expansion (see below) which means that rhizomes have a higher likelihood of 'filling in the gaps' with new crowns, leading to the observed higher crown density.

For $\delta \geq 10$ the area expansion curve is monotonically decreasing with increasing $\delta$ as expected. The low value for $\alpha$ for the biologically unlikely case $\delta=0$ 
is an artifact of the way the simulation works. The depth boundaries are zeroflux and if a segment exceeds the depth limit during its growth phase then it is adjusted such that its tip lies on the boundary. Therefore, since for $\delta=0$ there is no change of direction from one time-step to the next, once a segment reaches either boundary it will continue to grow along that boundary. As the simulation progresses this means that many rhizome segments will have grown beneath the maximum depth required for crown generation with no chance of re-entering the viable zone, resulting in an artificially reduced mean value for $\alpha$.

The fastest growth in area is exhibited in the range of $5-40^{\circ}$, after which area expansion becomes almost negligible in the studied time-scale. This is due to the generation of highly tortuous rhizome segments, resulting in a restricted outward expansion and, hence, a reduced growth rate. It is therefore likely that an appropriate value for $\delta$ lies within the range of $5-40^{\circ}$, which is also supported by the predicted mean crown density above. The case in which $\delta=180^{\circ}$ is equivalent to the rhizomes undertaking a simple random walk rather than a correlated one. However, we note that since growth is occuring, the $A \approx \alpha t^{2}$ behaviour is preserved in this case.

No stand deaths were observed for simulations run under all parameter values except $\delta=70$ ( 1 out of 9 trials) and $\delta=170$ ( 2 out of 46 trials).

\subsubsection{Probability of a Crown Forming, c}

Figure 11 shows the relationship between $c$, the probability of a crown forming at the tip of a rhizome segment given that all of the other prerequisite conditions have been met, and the mean crown density (left) and $\alpha$ (right). 

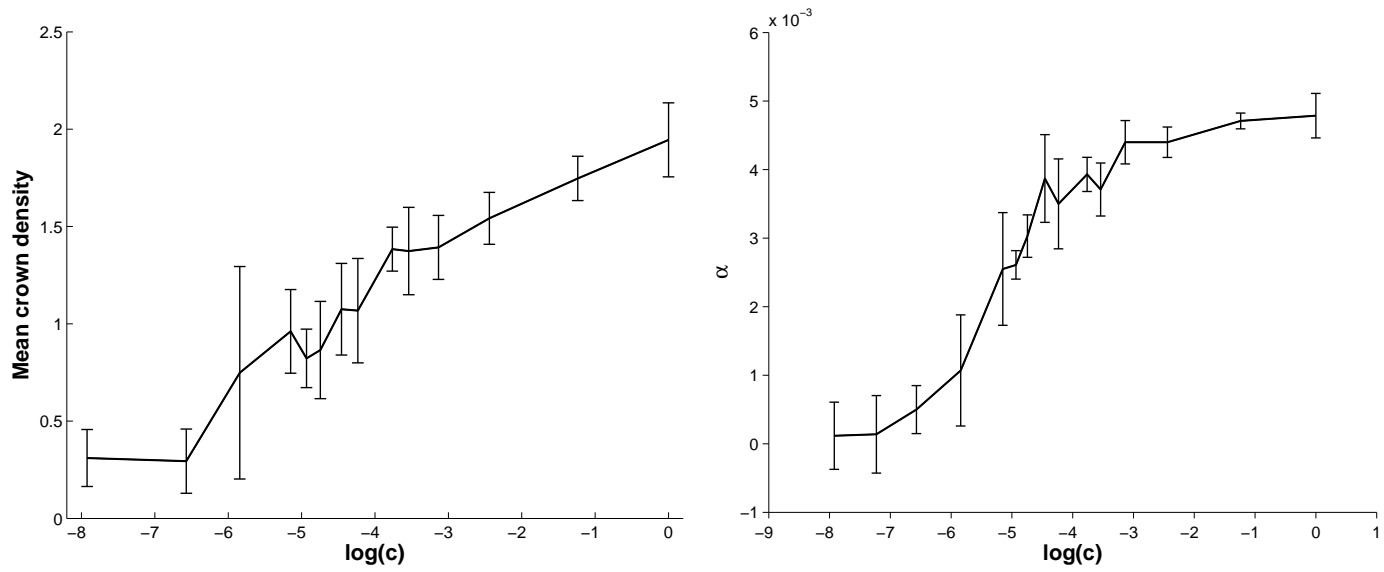

Fig. 11. The effects of $c$ on mean crown density (left, $3-18$ trials per data point) and growth parameter $\alpha$ (right, $3-14$ trials per data point). Bars indicate \pm 1 standard deviation. Other parameters in the trials are as given in Tab. 2.

The general trend exhibited by the mean crown density is monotonically increasing with $c$ as expected. The crown density observed in the field of 1.08 crowns $\mathrm{m}^{-2}$ suggests that an appropriate value for $c$ lies in the range 0.0029 0.0145 .

The general shape of the area curve indicates that $\alpha$ increases monotonically with $c$; the greatest change occuring between $c=0.005$ to $c=0.05$. For $c>0.05$ the intraspecific competition conditions play a much greater role in limiting the rate of area expansion due to the higher incidence of crown generation. For small $c$ the predicted mean value for $\alpha$ is very small and will vanish as $c \rightarrow 0$. This is mainly due to the fact that the probability of a segment 'dying' (no further growth permanently), $p_{d}$, becomes much larger than $c$ and hence rhizome segments are far more likely to die before they have a chance to develop a new crown.

No stand deaths were observed for simulations run under all parameter values except $c=0.0003625$ (3 out of 100 trials), $c=0.0014$ ( 2 out of 12 trials) and 
$c=0.0072$ (1 out of 6 trials).

\subsubsection{Probability of a Rhizome Remaining Stationary, $p_{p}$}

Figure 12 shows the relationship between $p_{p}$, the probability that a rhizome will not grow at any given time step, and the mean crown density (left) and $\alpha$ (right).
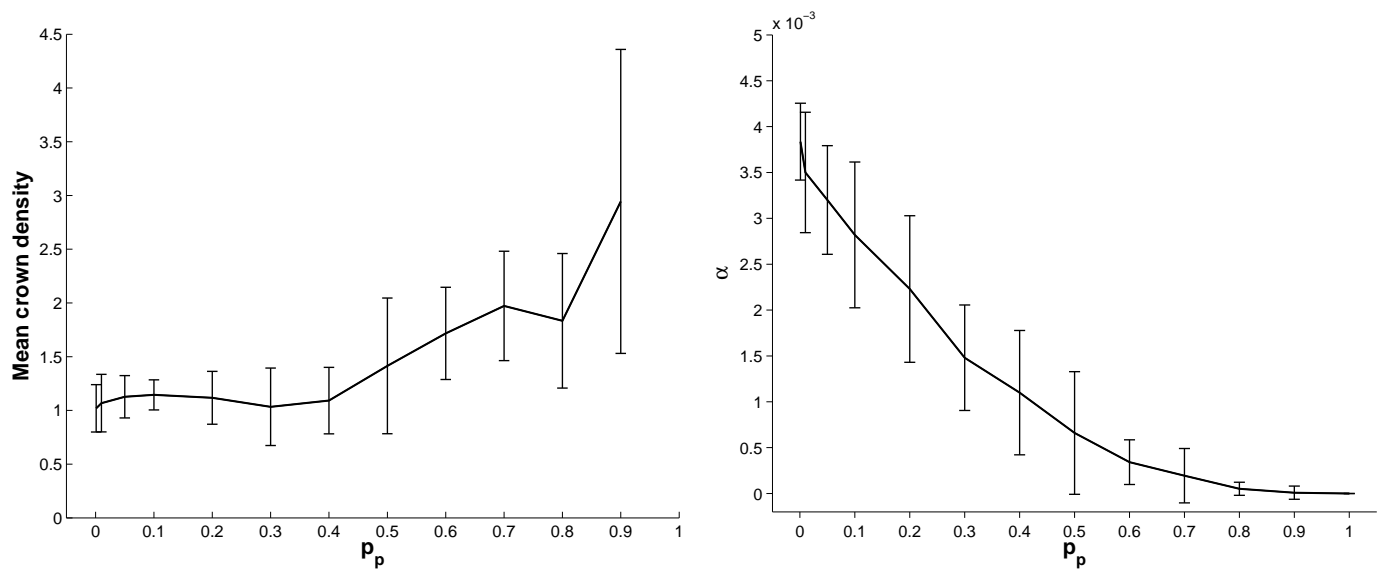

Fig. 12. The effects of $p_{p}$ on mean crown density (left, $7-18$ trials per data point) and growth parameter $\alpha$ (right, $6-14$ trials per data point). Bars indicate \pm 1 standard deviation. Other parameters in the trials are as given in Tab. 2.

The mean crown density predicted by the simulations is not significantly affected for $p_{p} \in[0,0.4]$ with predicted densities lying in the range 1-1.2 crowns $\mathrm{m}^{-2}$, but for $p_{p}>0.4$ the general trend is monotonically increasing with $p_{p}$. This is explained by the increase in time spent in viable areas due to the slower rate of extension caused by the increased incidence of rhizomes remaining stationary.

As expected, the rate of area expansion is greatest for $p_{p}=0$, for which there is no retardation of extension, and zero for $p_{p}=1$ since no growth will occur on any time scale. The growth rate of the stand decreases with increasing $p_{p}$ since 
each rhizome is less likely to survive to form a crown due to random expiration $\left(p_{d}\right)$ becoming an increasingly dominant factor. Indeed, no stand deaths were observed for simulations run under all parameter values except for $p_{p}=0.1$ ( 1 out of 10 trials), $p_{p}=0.8$ ( 2 out of 18 trials) and, most significantly, $p_{p}=0.9$ (30 out of 177 trials).

\section{Discussion}

The correlated random walk model discussed in this paper accurately predicts many of our field observations. Since the field data feature so heavily in the model, the simulation is able to produce realistic maps of a rhizome network's structure. As such it serves as a useful basis for more complex models in terms of a model free from any external influences such as management techniques, rhizome fragment transport in riparian environments or predation. The model could be used to predict the spread rates of existing stands or of new clones. Management of $F$. japonica infestations can be extremely costly and it would therefore be useful in the prioritisation and economic viability assessment of sites for treatment. It also facilitates the estimation of biomass for a specific stand, although further investigation of the variability in rhizome diameters may be necessary here.

Modelling the development of a rhizome network at a single clone scale necessitates the use of the third dimension. Although some exceptional stands can grow over $200 \mathrm{~m}^{2}$ in area, $30-100 \mathrm{~m}^{2}$ is more typical and at this scale the third dimension still plays a significant part in its development. Furthermore, the use of the third dimension in the correlated random walk is essential if we wish to utilise our field data which was itself gleaned from a 3D structure. 
Its inclusion not only represents the biology more closely, but key measurable data such as branching angles and segment lengths would be rendered irrelevant in a 2D model. Finally, 3D growth allows the rhizomes to circumnavigate obstacles in an inhomogeneous environment. The modular nature of the simulation allows for easy implementation of barriers to growth if required. Some of these are zero-flux (i.e. impenetrable) in nature, which may (e.g. walls and fences) or may not (e.g a road) generally be negotiable by the plant, but others may only affect growth rates (e.g poor or very dense substrate). The ability to overcome these impediments as the plant does in the wild is crucial to the formulation of a realistic model.

In this paper we constructed a 3D CRW model for the development of a rhizome network in the invasive weed $F$. japonica. The collection and subsequent use of field data in the parameterisation and validation of the modelling features strongly in this work and extensive study of the effects of the few remaining unknown parameters on the crown density and rate of stand area expansion was undertaken. The simulation demonstrated that the model solutions are robust to changes in parameters, in that a small parameter change only leads to a small quantitative change in results.

The quadratic expansion in time of a stand predicted by the model is entirely consistent with the large time behaviour of a general reaction-diffusion equation of the form

$$
\frac{\partial u}{\partial t}=D\left(\frac{\partial^{2} u}{\partial x^{2}}+\frac{\partial^{2} u}{\partial y^{2}}\right)+r f(u)
$$

where $u$ is the crown density, $f(u)$ is a suitable growth function, $D$ is the diffusion coefficient and $r$ is a growth rate constant. A very well studied form 
for $f(u)$ is $f(u)=u(1-u)$ where equation (2) is known as the Fisher equation (Murray, 1993) with carrying capacity scaled to unity. It can be shown that the radial expansion velocity, $c$, predicted by (2) is given by $c=2 \sqrt{r D}$ and hence $A \approx \pi c^{2} t^{2}=4 \pi r D t^{2}$. Consequently, we can relate this to the CRW model with

$$
\alpha=4 \pi r D
$$

by comparison with equation (1). Thus, a model like Fisher's equation should be a useful "phenomenological" equation for modelling stand expansion over longer timescales and larger spatial scales (e.g. 10-100 $\mathrm{m}^{2}$ ) because they are computationally more efficient to solve than the CRW model in such circumstances. Given appropriate field data the CRW model will allow the deduction of a realistic value for $\alpha$, which can then be used to estimate the product $r D$ (through equation 3). This can not be determined using our "snapshot" data which is based on fieldwork from a single visit.

There exists a wide scope for extending this work. Further field data are highly desirable in developing the model. Cain (1990) reports a wide variation in the clonal growth parameters (branching angles, rhizome lengths and number of daughter rhizomes) between different sample sites for Solidago altissima. The same is likely to be true for F. japonica, suggesting that an area for further research would be the collection of equivalent data to that used in this report from different habitat types. The areas sampled were representative of a typical roadside verge/woodland habitat. The fieldwork in Cornwall was carried out on the periphery of a large stand and studied relatively young crowns and rhizomes. Older rhizomes are known to grow to a much larger diameter and it would be interesting to compare their properties with the 
newer growth. The soil also contained a lot of dumped material such as slate, rubble, glass bottles and so on which is a typical feature of the way in which F. japonica is spread by human activity, particularly fly-tipping. However, it only represents a single sample stand from a single habitat type. There are many different environments in which $F$. japonica may be found, e.g. sand dunes or river gravel, and it is reasonable to assume that its behaviour might be different in each. As well as the habitat type, environmental conditions such as $\mathrm{pH}$ values, availability of water, soil stability, water-tables, mineral content, altitude, sources of light and competition vary considerably and all play a significant part in the performance of the plant. It would be interesting to see how our data compare against variations in any of these factors. As mentioned above, the properties of the long time spread on a larger scale may be determined from this model and so the investigation of field spread rates would therefore be extremely useful, particularly in validating the quadratic expansion in time of the stand area predicted by the CRW model. It would also facilitate the assignment of an appropriate value to $\alpha$, which could then be referenced against the parameter surveys to select appropriate parameter values for those that remain unknown.

The model itself may also be extended in a number of ways. Hormonal signals play a major role in the control of apical dominance, branching and crown formation. Our model is phenomenological and a more biologically accurate mechanism could be included for such hormonal control. Another area for further development of the model would be to include the effects of some of the management techniques employed to control the spread of F. japonica. Of particular interest here would be the effects of different herbicides or a future biocontrol agent. 


\section{Acknowledgements}

The first author gratefully acknowledges the funding support of Loughborough University.

\section{References}

Adachi, N., Terashima, I., Takahashi, M., 1996a. Central die-back of monoclonal stands of Reynoutria japonica in an early stage of primary succession on Mount Fuji. Annals of Botany 77, 477-486.

Adachi, N., Terashima, I., Takahashi, M., 1996b. Mechanisms of central dieback of Reynoutria japonica in the volcanic desert on Mt. Fuji. A stochastic model analysis of rhizome growth. Annals of Botany 78, 169-179.

Bailey, J. P., 2003. Japanese knotweed s.l. at home and abroad. In: Child, L. E., Brock, J. H., Brundu, G., Prach, K., Pysek, P., Wade, P. M., Williamson, M. (Eds.), Plant Invasions: Ecological Threats and Management Solutions. Backhuys Publishers, Leiden, The Netherlands, pp. 183-196.

Beerling, D. J., 1993. The impact of temperature on the Northern distributionlimits of the introducedspecies Fallopia japonica and Impatiens glandulifera in North-West Europe. Journal of Biogeography 20(1), 45-53.

Beerling, D. J., Bailey, J. P., Conolly, A. P., 1994. Biological flora of the British Isles. Fallopia japonica (Houtt.) Ronse Decraene. Journal of Ecology 82, 959-979.

Beerling, D. J., Huntley, B., Bailey, J. P., 1995. Climate and the distribution of Fallopia japonica - use of an introduced species to test the predictive capacity of response surfaces. Journal of Vegetation Science 6(2), 269-282.

Brabec, J., Pysek, P., 2000. Establishment and survival of three invasive taxa 
of the genus Reynoutria (Polygonaceae) in mesic mown meadows: A field experimental study. Folia Geobotanica 35(1), 27-42.

Brock, J. H., Child, L. E., de Waal, L. C., Wade, M., 1995. The invasive nature of Fallopia japonica is enhanced by vegetative regeneration from stem tissues. Plant Invasions - General Aspects and Special Problems, SPB Academic Publishing, 131-139.

Brock, J. H., Wade, M., 1992. Regeneration of Japanese knotweed (Fallopia japonica) from rhizomes and stems: Observations from greenhouse trials. Proceedings 9th International Symposium on the Biology of Weeds, Dijon, France, 85-94.

Cain, M. L., 1990. Models of clonal growth in Solidago altissima. Journal of Ecology 78, 27-46.

Child, L. E., 1999. Vegetative regeneration and distribution of Fallopia japonica and Fallopia $x$ bohemica: Implications for control and management. Ph.D. thesis, Loughborough University, UK.

Child, L. E., de Waal, L., 1997. The use of G.I.S. in the management of Fallopia japonica in the urban environment. In: Brock, J. H., Wade, M., Pysek, P., Green, D. (Eds.), Plant Invasions: Studies from North America and Europe. Backhuys Publishers, Leiden, The Netherlands, pp. 207-220.

Child, L. E., Wade, M., 1999. Fallopia japonica in the British Isles: the traits of an invasive species and implications for management. In: Yano, E., Matsuo, K., Shiyomi, M., Andow, D. A. (Eds.), Biological Invasions of Ecosystems by Pests and Beneficial Organisms, NIAES Series 3. National Institute of Agro-Environmental Sciences, Tsukuba, Japan, pp. 200-210.

Child, L. E., Wade, M., 2000. The Japanese Knotweed Manual. Packard Publishing Limited, Chichester.

Child, L. E., Wade, M., Hathaway, S., 2001. Strategic invasive plant man- 
agement, linking policy and practice: A case study of Fallopia japonica in Swansea, South Wales (United Kingdom). In: Brundu, G., Brock, J., Camarda, I., Child, L., Wade, M. (Eds.), Plant Invasions: Species Ecology and Ecosystem Management. Backhuys Publishers, Leiden, The Netherlands, pp. 291-302.

Child, L. E., Wade, M., Wagner, M., 1998. Cost effective control of Fallopia japonica using combination treatments. In: Starfinger, U., Edwards, K., Kowarik, I., Williamson, M. (Eds.), Plant Invasions: Ecological Mechanisms and Human Responses. Backhuys Publishers, Leiden, The Netherlands, pp. $143-154$.

Collingham, Y. C., Wadsworth, R. A., Huntley, B., Hulme, P. E., 2000. Predicting the spatial distribution of non-indigenous riparian weeds: Issues of spatial scale and extent. Journal of Applied Ecology 37 (Suppl.1), 13-27.

Conolly, A. P., 1977. The distribution and history in the British Isles of some alien species of Polygonum and Reynoutria. Watsonia 11, 291-311.

Crawley, M. J., 1987. What makes a community invasible? In: Gray, A. J., Crawley, M. J., Edwards, P. J. (Eds.), Colonization, Succession and Stability. Symposia of the British Ecological Society, 26. Blackwell Scientific Publications, Oxford, pp. 429-454.

Crawley, M. J., 1989. Chance and timing in biological invasions. In: Drake, J. A., Mooney, H. A., di Castri, F., Groves, R. H., Kruger, F. J., Rejmánek, M., Williamson, M. (Eds.), Biological invasions: a global perspective. SCOPE 37, pp. 407-424.

Dawson, F. H., Holland, D., 1999. The distribution in bankside habitats of three alien invasive plants in the UK in relation to the development of control strategies. Hydrobiologia 415, 193-201.

de Waal, L. C., 2001. A viability study of Fallopia japonica stem tissue. Weed 
Research 41, 447-460.

di Castri, F., Hansen, A. J., Debussche, M. (Eds.), 1990. Biological invasions in Europe and the Mediterranean basin. Kluwer, Dordrecht.

Forman, J., Kesseli, R. V., 2003. Sexual reproduction in the invasive species Fallopia japonica (Polygonaceae). American Journal of Botany 90(4), 586592.

Green, S., 2003. A review of the potential for the use of bioherbicides to control forest weeds in the UK. Forestry 76(3), 285-298.

Hall, R. L., 1977. Amoeboid movement as a correlated random walk. Journal of Mathematical Biology 4, 327-335.

Hathaway, S., 2000. Surveys on the spread of Japanese knotweed (Fallopia japonica) in Swansea and strategies for its control. Aspects of Applied Biology $58,55-62$.

Hollingsworth, M. L., Bailey, J. P., 2000. Evidence for massive clonal growth in the invasive weed Fallopia japonica (Japanese knotweed). Botanical Journal of the Linnean Society 133(4), 463-472.

Hollingsworth, M. L., Hollingsworth, P. M., Jenkins, G. I., Bailey, J. P., Ferris, C., 1998. The use of molecular markers to study patterns of genotypic diversity in some invasive alien Fallopia spp. (Polygonaceae). Molecular Ecology 7(12), 1681-1691.

Hulme, P. E., 2003. Biological invasions: Winning the science battles but losing the conservation war? Oryx 37(2), 178-193.

Kareiva, P., Shigesada, N., 1983. Analyzing insect movement as a correlated random walk. Oecologia 56, 234-238.

Kim, J. Y., Park, C. W., 2000. Morphological and chromosomal variation in Fallopia section Reynoutria (Polygonaceae) in Korea. Brittonia 52(1), 3448. 
Mack, R. N., 1986. Alien plant invasion into the intermountain west: A case history. In: Mooney, H. A., Drake, J. A. (Eds.), Ecology of biological invasions of North America and Hawaii. Springer-Verlag, New York, pp. 191211.

Murray, J. D., 1993. Mathematical Biology, 2nd Corr. Ed. Springer-Verlag, Berlin.

Price, E. A. C., Gamble, R., Williams, G. G., Marshall, C., 2002. Seasonal patterns of partitioning and remobilization of C-14 in the invasive rhizomatous perennial Japanese knotweed (Fallopia japonica (Houtt.) Ronse Decraene). Evolutionary Ecology 15(4-6), 347-362.

Pysek, P., 1997. Clonality and plant invasions: can a trait make a difference? In: de Kroon, H., van Groenendael, J. (Eds.), The Ecology and Evolution of Clonal Plants. Backhuys Publishers, Leiden, The Netherlands, pp. 405-427.

Pysek, P., Prach, K., 1993. Plant invasions and the role of riparian habitats: a comparison of four species alien to Central Europe. Journal of Biogeography 20, 413-420.

Pysek, P., Prach, K., Smilauer, P., 1995. Relating invasion success to plant traits: an analysis of the czech alien flora. In: Pysek, P., Prach, K., Rejmánek, M., Wade, M. (Eds.), Plant invasions: general aspects and special problems. SPB Academic Publishing, Amsterdam, The Netherlands, pp. 39-60.

Seiger, L. A., Merchant, H. C., 1997. Mechanical control of Japanese knotweed (Fallopia japonica (Houtt.) Ronse Decraene): Effects of cutting regime on rhizomatous reserves. Natural Areas Journal 17(4), 341-345.

Thuiller, W., Araujo, M. B., Lavorel, S., 2003. Generalized models vs. classification tree analysis: Predicting spatial distributions of plant species at different scales. Journal of Vegetation Science 14(5), 669-680. 
Tickner, D. P., Angold, P. G., Gurnell, A. M., Mountford, J. O., 2001. Riparian plant invasions: hydrogeomorphological control and ecological impacts. Progress In Physical Geography 25(1), 22-52. 